\title{
INOVAÇÃO EM ESCOLAS PÚBLICAS DE NÍVEL BÁSICO: O CASO REDES DA MARÉ (RIO DE JANEIRO, RJ)*
}

\author{
Elie GEORGE GUIMARÃEs GHANEM JÚNIOR*
}

\begin{abstract}
RESUMO: Este trabalho apresenta os resultados de um estudo de caso de inovação educacional na atuação de uma organização não governamental (ONG) junto a escolas públicas de educação básica no Complexo da Maré, Rio de Janeiro (RJ). A hipótese examinada pela pesquisa foi a de que fatores salientes que se conjugam na geração de ações de inovação são o tempo de experiência profissional de educadores(as), a estabilidade de sua equipe, o nível de qualificação e a atuação mobilizadora de líderes da ONG. São descritos os objetivos e características da atuação da ONG e são apontadas as características de líderes, agentes e equipes. Em conclusão, a hipótese levantada é aceita.
\end{abstract}

Palavras-chave: Inovação educacional. Reforma educacional. Rio de Janeiro.

$$
\begin{aligned}
& \text { INNOVATION IN BASIC LEVEL PUBLIC SCHOOLS: } \\
& \text { THE CASE OF "REDES DA MARÉ" (RIO DE JANEIRO, RJ) }
\end{aligned}
$$

ABSTRACT: This article presents the results of an educational innovation case study resulting from a NGO's operation along with basic public schools at Complexo da Maré, Rio de Janeiro, RJ. The research examines the hypothesis that the interrelated proeminent factors that generate educational innovation are: length of educators' professional experience, team's stability, NGO leaders' qualification level and their mobilizing action. The NGO's objectives and work characteristics are described, as well as the characteristics of leaders, education agents and teams. In conclusion, the proposed hypothesis is accepted.

Key words: Educational innovation. Educational reform. Rio de Janeiro.

Pesquisa realizada com apoio da Fundação de Amparo à Pesquisa do Estado de São Paulo (Fapesp).

** Doutor em Educação e professor da Faculdade de Educação da Universidade de São Paulo (USP). E-mail:<elie@usp.br> 


\section{INNOVATION DANS DES ÉCOLES PUBLIQUES D'ENSEIGNEMENT} DE BASE: LE CAS “REDES DA MARÉ" (RIO DE JANEIRO, RJ)

RÉSUMÉ: Cet article présente les résultats d'une étude de cas d'innovation scolaire dans ce cadre: une ONG auprès des écoles publiques de formation initiale au Complexo da Marée, à Rio de Janeiro, RJ. L'hypothèse examinée par la recherche est que les principaux facteurs qui se conjuguent dans l'origine des innovations éducatives sont: le temps d'expérience professionnelle des enseignants, la stabilité des équipes, le niveau de qualification et la performance mobilisatrice des dirigeants de l'ONG. Les objectifs et les caractéristiques de la performance de l'ONG sont décrits bien que celles des dirigeants, des agents et des équipes. Pour conclure, l'hypothèse soulevée est acceptée.

Mots-clés: Innovation d'enseignement. Réforme d'enseignement. Rio de Janeiro.

\section{Introdução}

A s abordagens da inovação educacional geralmente utilizam indistintamente os termos inovação, mudança, transformação e outros com intenção de significar esforços para alterar práticas educacionais. Estudos destacados, tais como Huberman (1976), tratam do fenômeno com variados termos, ainda que assinalem diferenças de escala. Assim, identificam que a mudança ou a inovação pode se dar em uma ou em um pequeno conjunto de escolas, como pode também abranger a rede escolar de uma província ou estado, de uma região ou de um país. Nestes últimos casos, as obras se referem diversas vezes ao fenômeno com a expressão "reforma educacional" (CRAIG, 2001a, 2001b; HATCH, 2001; DRAKE; SHERIN, 2006). Muitas pesquisas procuraram identificar as razões pelas quais reformas educacionais não lograram alterar as práticas correntes e, neste sentido, não conseguiram inovar segundo os reformadores pretendiam (TYACK; CUBAN, 1995; FARRELL, 2000, 2001; DIDASKALOU, 2002; LAWTON, 2001; GLÓRIA; MAFRA, 2004; LEVIN, 2008; TURA; MARCONDES, 2008). A pesquisa da qual se originou este artigo enfoca a inovação educacional como práticas independentes da atuação reformadora de governantes e o principal problema de pesquisa colocado foi: que fatores se conjugam na geração de ações de inovação educacional?

Contribuições como as de Parsons e Fidler (2005) são muito profícuas, pois mostram que a mudança planejada ora é interpretada como mudança radical de larga escala, ora como pequenas mudanças incrementais e, às vezes, como combinações destas com aquela em longos períodos de equilíbrio. Reconhecendo este tipo de variação, a abordagem adotada aqui utiliza uma nomenclatura formulada a partir da análise de Torres (2000) sobre os percalços da mudança educacional decorrentes do caráter das relações entre reformadores e docentes. A nomenclatura que emprego diferencia mudança educacional de reforma educacional e de inovação educacional. Eu 
atribuo a expressão mudança educacional à mudança radical de grande escala, que se pode chamar de sistêmica. Trata-se de um processo que resulta da convergência de práticas situadas em duas lógicas: a lógica da inovação educacional e a da reforma educacional. Desse modo, a inovação educacional tende muito mais ao endógeno que ao exógeno, diz respeito a práticas que se caracterizam pelo isolamento, fragmentação, descontinuidade no tempo, baixa visibilidade das ações e forte voluntarismo de educadores(as). São práticas que se originam tipicamente na base de sistemas escolares, ou seja, em estabelecimentos individualmente considerados ou em organizações de alcance local, geralmente conhecidas como associações comunitárias. Essencialmente, as práticas de inovação não se caracterizam pelo ineditismo, mas por serem atividades diferentes daquelas que seguem um costume em um determinado lugar e grupo social. São inovadoras em relação a este costume.

Eu emprego a expressão "reforma educacional" para designar a lógica que preside práticas não criadas por agentes diretos de sua execução. Tendem muito mais ao exógeno que ao endógeno, já que são prescritas por autoridades (em geral, autoridades estatais do Poder Executivo e autoridades acadêmicas das universidades) e sua sustentabilidade lhe dá permanência, sobretudo por contar com recursos orçamentários do poder público. O caráter destas práticas é normativo e impositivo, sua abrangência é ampla, seu formato é homogêneo e sua visibilidade é alta.

Sublinhe-se que a investigação de quaisquer alterações que possam ocorrer em práticas educacionais, sejam as abarcadas pela reforma ou pela inovação, não implica necessariamente atribuir um valor positivo ou negativo a tais fenômenos. Como adverte Craft (2003), nenhuma daquelas alterações é algo que possa ser considerado bom em si mesmo.

Muitos aspectos são relevantes para compreender as ações a que obedecem cada uma das lógicas. A pesquisa que apresento neste texto se concentrou nos fatores que estariam propriamente na gênese das experiências inovadoras. Descartei a atuação dos níveis hierárquicos mais elevados da administração dos sistemas escolares ou dos aparatos estatais de maneira geral, priorizando a hipótese de que os fatores salientes que se conjugam são a experiência profissional de docentes, a estabilidade de corpos docentes, a atuação mobilizadora de diretores(as) de estabelecimentos e o grau de qualificação profissional de integrantes de organizações comunitárias. Para examinar a veracidade desta hipótese, realizei o estudo de quatro casos de inovação empreendidos por organizações não governamentais (ONGs) nos estados brasileiros de Amazonas, Ceará, Pernambuco e Rio de Janeiro. Os resultados deste útimo são descritos neste artigo.

Como se tratava de ONGs e não de escolas comuns, adequei os fatores priorizados na hipótese. Assim sendo, como tempo de experiência de docentes na profissão 
foi considerado o tempo dos(as) agentes educadores(as) das ONGs, e sua estabilidade na função foi tomada como equivalente da estabilidade de corpos docentes em escolas. A atuação mobilizadora de diretores(as) de estabelecimentos passou a corresponder à de líderes das ONGs. O seu nível de qualificação profissional, por sua vez, assumiu o lugar do nível de líderes de associações comunitárias.

As informações utilizadas foram colhidas ao longo de 2010, em visitas a diferentes lugares do Complexo da Maré, em entrevistas semiestruturadas com dirigentes e agentes educacionais da organização Redes de Desenvolvimento da Maré e em suas publicações.

\section{O caso Redes da Maré}

\section{Redes de desenvolvimento e Programa Criança}

O chamado Complexo da Maré é uma favela com cerca de 130 mil habitantes, em16 comunidades (equivalentes aproximadamente a bairros) com 16 escolas, a maioria de ensino fundamental e poucas vagas no nível médio. Em 8 de março de 2007, a Redes (Redes de Desenvolvimento da Maré) foi formalmente fundada por um grupo que, por mais de dez anos, atuava no Centro de Estudos e Ações Solidárias da Maré (Ceasm). Este, por sua vez, teve início com o curso pré-vestibular, que teve continuidade sob a responsabilidade da Redes da Maré e contava com três turmas em 2010.

A Redes está sediada em quatro prédios e sua diretoria é composta de quatro pessoas, moradoras ou ex-moradoras (REDES, 2011). O grupo não considera este fato um detalhe e, segundo uma coordenadora de projeto, "é bastante diferente de uma ONG que são pessoas de fora, que entram numa favela para montar algum trabalho e não têm a noção da realidade daquela comunidade, das necessidades, das demandas".

Uma das principais ações é o programa Criança, junto a nove estabelecimentos públicos: oito escolas de ensino fundamental e uma creche. Há também um curso preparatório para provas de seleção para o $6^{\circ}$ ano de estabelecimentos públicos considerados "de qualidade" (Colégio Pedro II, Colégio de Aplicação da Uerj, Colégio de Aplicação da UFRJ). Na mesma linha, há um preparatório para provas de ingresso em escolas técnicas de nível médio. A Redes oferece também cursos de idiomas (inglês, francês e espanhol), um curso de fotografia e um de teatro. Num dos prédios, funciona a biblioteca comunitária e, em outro, um laboratório de informática que também realiza cursos.

O programa Criança iniciou em 2001, visando contribuir com a qualidade da educação em termos de desempenho escolar das crianças (REDES, 2011a). Uma de 
suas coordenadoras afirma haver muitas "crianças com dificuldade de aprendizado", que já passsaram pelos três primeiros anos do ensino fundamental e "mal sabem escrever seus nomes". O programa é dirigido a alunos(as) das escolas locais e suas famílias. Uma das linhas de ação é a arte-educação, com projetos dentro de cada uma das escolas: de circo, de orquestra, de canto coral, de maracatu, de batuque e de dança contemporânea. Num dos prédios da Redes, há ensino de desenho, de arte sobre azulejo, de grafitti e de break.

Segundo uma coordenadora, as crianças participantes dos grupos de arte-educação melhoraram significativamente seu desempenho escolar, mas não conseguiam se alfabetizar. Em 2009, decidiu-se que todas "teriam que fazer parte das aulas de reforço escolar". Duas vezes por semana, as crianças realizam atividades de arte e outras duas vezes têm aula do que é chamado de complementação escolar, planejada "em parceria" com docentes das escolas: "é o reforço escolar, de uma forma mais lúdica, numa metodologia um pouco diferenciada da escola". Inicialmente, era obrigatória, mas muitas crianças não compareciam, nem todas precisavam e, em 2010, o reforço escolar foi desvinculado da arte-educação.

Mas também muitas compareciam ao reforço e a coordenadora supõe que seja devido à "parceria com as famílias", que talvez tenham obrigado as crianças a frequentar. Seis professoras da Redes trabalham somente com crianças de $3^{\circ}$ e $4^{\circ}$ ano que ainda não se alfabetizaram, mediante a concordância delas e de seus familiares.

Toda escola municipal tem uma sala de leitura, mas, de acordo com a coordenadora do programa Criança, até que o trabalho da Redes da Maré "entrasse naquelas oito escolas", as salas de leitura não eram utilizadas. Devido à insuficiência do número de docentes, orientadores(as) de sala de leitura a abandonavam para assumir turmas. Uma educadora da Redes afirmou haver acervos muito bons, mas que ninguém toca porque a mentalidade predominante é: "criança não leva livro porque criança rasga, criança não devolve livro". Assim, foi proposto um projeto no qual, em cada sala de leitura das oito escolas, há uma estudante da área de letras ou de pedagogia e uma contadora de histórias. Em parceria com as professoras orientadoras de salas de leitura, fizeram a informatização, a organização e a limpeza das salas, passaram a fazer empréstimos e contação de histórias para as turmas, pelo menos uma vez por semana.

Outra linha de atuação é chamada de trabalho social, realizada por uma equipe de assistentes sociais e psicólogos(as), que se voltam às famílias do conjunto de cada escola. Convidam-nas para um "grupo de pais" com o objetivo de promover a participação comunitária. Levam pessoas para proferir palestras e são feitas dinâmicas em grupos para estimular a expressão de participantes em temas trazidos pela equipe ou que surgem do próprio grupo, tais como sexualidade e comunidades com 
muitos conflitos (armados, envolvendo criminosos e policiais). Na favela, atuam três facções criminosas rivais, que estabelecem fronteiras e ameaçam principalmente jovens do sexo masculino que transitam entre elas.

A maioria das escolas da Maré não faz o horário de recreio em área externa porque os(as) professores(as) têm medo que "aconteça alguma coisa com as crianças". Uma entrevista para esta pesquisa foi interrompida três vezes pelo som de helicópteros da polícia e fogos de artifício, modo de alerta dos grupos criminosos locais. A educadora entrevistada comentou: “Nós não fechamos, nós não paramos. As escolas, às vezes, param. Nós, não". Uma coordenadora do programa explica as condutas docentes pelo fato de muitos(as) serem "de fora" e terem pouquíssimo envolvimento com a realidade da Maré. Ela disse que todas as escolas dispensam as turmas às $15 \mathrm{~h} 30 \mathrm{~min}$ e não no horário regular das $17 \mathrm{~h}$, por medo de haver tiroteio, e esta prática tornou-se um costume.

Por fim, na atuação da ONG, há também uma linha chamada de formação. Quinzenalmente, a equipe toda do programa se reúne para tratar de temas gerais, exibir um vídeo sobre educação ou trazer alguém para fazer uma palestra. Há também reuniões quinzenais de coordenadoras por escolas, quando trocam sugestões sobre situações cotidianas, dificuldades, formas de enfrentamento de evasão das oficinas e grau de realização do trabalho proposto. Há também reuniões somente de educadores(as), somente de coordenadores(as) ou da "equipe social".

Profissionais das escolas, no entanto, não contam com uma linha regular de atividades de formação e a contribuição da Redes da Maré neste aspecto é inconstante. Em uma das escolas, por exemplo, foi escolhido "África" como tema central a ser tratado em 2010, tanto porque a Copa do Mundo de futebol foi na África do Sul, quanto porque a Lei n. 10.639/2003 exige abordar cultura africana e afro-brasileira. Uma reunião foi conduzida pelo pessoal da Redes, com apresentações de trabalhos de educadores(as) e distribuição de materias informativos, subsidiando o planejamento das atividades do corpo docente.

O programa se originou de uma proposta de patrocínio da empresa Petrobras ao Ceasm, que fez uma contraproposta: as atividades, antes previstas para ocorrer em instalações da empresa, seriam realizadas no Complexo da Maré e dentro de escolas municipais, tendo em vista contribuir para a qualidade de seu ensino. $\mathrm{O}$ programa era reformulado a cada ano. Durante 2008, o programa não esteve ativo porque estava em negociação com a empresa. A partir de 2009, deixou de ser revisto anualmente e passou a contar com recursos financeiros por um período de três anos.

Para viabilizar o trabalho, inclusive para a reabertura das salas de leitura, houve um processo de negociação com o órgão de nível intermediário da Secretaria Municipal de Educação e com profissionais nas escolas. Em 2009, a Secretaria também 
aceitou a proposta da Redes para realizar um seminário com professores(as) das 16 escolas da Maré, sobre "questões do ensino fundamental", exemplificadas como evasão, estrutura, violência, horário e material didático. Estiveram presentes no seminário cerca de 350 docentes, com remuneração da Secretaria pela atividade. Metade do período foi usada para grupos por escola responderem um questionário preparado pela Redes, opinando sobre pontos que requeriam mudança e fazendo sugestões.

\section{Articulação}

Embora seja uma das principais, o programa Criança é apenas uma das intervenções da Redes da Maré, que abrange desenvolvimento local, educação, comunicação, segurança pública e arte e cultura. O programa se organiza com responsáveis pela coordenação do trabalho por escola. Dado o acúmulo de tarefas nesta função, criou-se outra denominada mobilizadores institucionais (seis estudantes de nível superior que moram na Maré) para fazer com que o conjunto de profissionais de cada escola conheça e entenda o trabalho da Redes, de modo que este ocorra em "parceria com a escola". Mas as jornadas docentes são muito desfavoráveis, destinadas quase exclusivamente para aulas, com uma parte muito pequena para outras atividades.

No início do ano, o pessoal da Redes faz o que chamam de "chegança", quando apresentam para todas as crianças e docentes tudo o que fazem na escola. É um evento com atividades programadas para a quadra de esportes, há divulgação por meio de cartazes e avisos orais em salas de aula.

Na creche, as educadoras têm reuniões mensais de planejamento, dia em que as crianças não comparecem. Para as escolas, a Secretaria da Educação definiu oficialmente uma pequena parte da jornada docente, denominada centro de estudos (CE). No dia em que há $\mathrm{CE}$, o corpo docente tem duas horas sem crianças para se reunir. Duas vezes por ano, também acontece o centro de estudos maior, em maio e em agosto, quando não há aulas por um período inteiro. Algumas vezes, agentes da Redes da Maré têm autorização para falar com docentes nestes momentos. Outras vezes, procuram docentes para conversar nos horários em que há aula de Educação Física e as turmas estão com colegas desta área. Uma educadora descreveu assim as suas tentativas: "a gente, o tempo todo, tem que estar ali. O professor vai tomar cafezinho, a gente já está na cola dele. Cercando os caras".

A disposição de docentes para conversar é variável, dependente também da aceitação de profissionais com função técnica na escola: diretor(a) e coordenador(a) pedagógico(a). Como disse uma educadora da Redes: "todo trabalho que a gente faz a gente senta com eles, a gente planeja juntos. É muito bacana. [...] Se esta articulação é mais tranquila, mais aberta, com os professores, vai ser mais ou menos uma consequência". 
Uma coordenadora do programa acredita que o seminário realizado com docentes trouxe maior credibilidade para a Redes e que estão conseguindo êxito em mostrar que o pessoal da Redes está lá para contribuir de fato, em parceria na qual docentes possam interferir e propor. Para uma arte-educadora, docentes das escolas em que ocorrem as oficinas do programa gostam muito deste trabalho, a relação com os corpos docentes é muito forte e não teriam como fazer tal trabalho "durante dez anos sem existir essa parceria". Outra coordenadora do programa declarou também que uma parte dos corpos docentes gosta muito da visão de educação e da atuação da Redes, compartilha das ideias e sugestões trazidas, junta-se e participa.

No entanto, o programa Criança esteve inativo durante 2008, enquanto foi renegociado e, quando as atividades retornaram, as direções e docentes das escolas informaram não terem dado continuidade ao trabalho que era feito pela Redes. Segundo uma das coordenadoras do programa, não se pretende que o trabalho seja permanente, sendo feito para mostrar a possibilidade de uma escola de maior qualidade. Sua expectativa é que o poder municipal inclua em seu planejamento o tipo de atividades que a Redes da Maré realiza. No entanto, decepcionada, a coordenadora viu que, na maioria das escolas, nem houve o cuidado com próprio espaço que era utilizado. Sua explicação do desprezo pelo trabalho está na visão de uma injusta diferença de condições, como se dissessem: “É muito fácil. Você vem aqui três horas e pouco por semana, faz seu trabalhinho lá de arte-educação, com as crianças que querem. Quem pega no pesado somos nós, que ganhamos mal. Provavelmente vocês ganham muito bem".

\section{A origem da demanda}

A intervenção foi proposta a partir de uma interpretação do pessoal da Redes da Maré quanto à educação escolar na favela. O programa Criança não foi uma resposta a alguma insatisfação oriunda das escolas, apontada por profissionais, estudantes ou seus familiares. O programa propôs um modo de fazer até então inexistente. $\mathrm{O}$ pessoal da Redes acredita que as linguagens artísticas contribuem "para a formação do sujeito" e nenhuma escola da Maré as oferecia. Ao entrar na escola para este trabalho, notou "muitas outras faltas", por exemplo, em relação à leitura e à escrita, e o não funcionamento das salas de leitura. Daí ter sido proposto também um trabalho em sala de leitura, com contação de histórias e estímulo à leitura, à escrita e à expressão oral.

Todos os depoimentos obtidos na pesquisa fizeram menção à necessidade de entender que cada escola tem sua peculiaridade e que cada diretora recebe a proposta da Redes de um modo diferente. Com algumas, "não tem entrada fácil, tem que ficar ali insistindo, insistindo". Algumas diretoras não permitiram que o pessoal 
da Redes criasse o grupo de pais ou participasse de reuniões de conselho de classe (momento em que docentes de uma turma se reúnem para julgar o desempenho de estudantes). Segundo uma educadora, estas diretoras tinham receio de que se tornasse um lugar para reclamar e falar mal delas.

Conforme afirmou um integrante da diretoria da Redes da Maré, esta foi motivada por focalizar os seguintes pontos: a maioria dos Centros Integrados de Educação Pública (Cieps) deveria funcionar em período integral e reduziu para turno parcial; docentes faltavam muito às aulas; não havia número suficiente de docentes; a evasão e a reprovação eram altas; a qualidade das aulas era ruim porque havia "alunos que chegavam à $5^{\underline{a}}$ série analfabetos ou semianalfabetos". Formulou-se uma ação para ajudar as escolas a superar tais aspectos: "a ideia nunca foi montar uma escola paralela ou fazer o que a escola teria que fazer". Mas aquele integrante afirmou que, no início, havia muita tensão em algumas escolas, decorrente da desconfiança de docentes quanto ao propósito do trabalho: "em algumas escolas, levou até alguns anos para a gente chegar a um grau de entendimento bom como tem hoje. Hoje, na maioria, a gente tem bom relacionamento com a escola e acho que a escola entende muito mais o nosso trabalho. Isso depois de 10 anos". O receio de docentes é visto por aquele mesmo integrante da Redes como efeito de uma formação orientada para não dividir o trabalho com suas turmas, também do ciúme em relação às que são consideradas "as suas crianças", do medo de a atuação de outro educador evidenciar insuficiências de seu trabalho e de um frágil entendimento e desinteresse pela proposta da ONG.

De todo modo, em algumas escolas, quando os(as) professores(as) são convidados a participar das atividades da Redes com as crianças, saem e vão fazer outra coisa: "tem professor que torce o nariz, não deixa [a criança] ensaiar, diz que vai atrasar a matéria...". Este alheamento frustra o pessoal da Redes porque, como disse uma educadora, sua intenção era que sua atuação, "de alguma forma, respingasse no trabalho" que a professora estava fazendo.

Para uma responsável da Redes pela coordenação da atuação por escolas, o mais importante é fazer com que os professores tenham uma visão crítica do seu próprio trabalho, queiram se formar e se colocar na busca de que o seu trabalho melhore. Ao contrário disto, ela afirmou que, muitas vezes, docentes explicam "o baixo desempenho do aluno" pela ausência da família e de seu estímulo, pela pobreza e violência da comunidade, de modo que o(a) professor(a) retira sua responsabilidade diante do processo de aprendizagem.

A indisposição ao diálogo implica, algumas vezes, agentes da Redes ficarem esperando durante uma hora, tentando agendar um encontro. Oportunidades ainda mais raras em escolas que começaram a oferecer o segundo segmento do ensino 
fundamental, no qual as turmas têm docentes de várias disciplinas que comparecem à escola em diferentes dias e horários. Os momentos oficiais de centros de estudos, de acordo com uma educadora, "servem para tudo menos para estudo". Tratam de assuntos administrativos, lançar notas, relatório para o órgão superior, corrigir provas ou negócios alheios à escola, tais como venda de cosméticos, alimentos e roupas. Ao longo dos anos, agentes da Redes vieram procurando participar dos centros de estudos. Os contatos iniciais com cada docente ocorrem, muitas vezes, pouco antes do horário da aula, interrompendo-a, ou assim que esta termina. Há docentes que almoçam na escola, momento que também é aproveitado para tentar o diálogo ou agendar uma conversa.

As razões da conduta docente convencional são atribuídas à desvalorização do magistério e ao abandono das escolas da favela pelo poder público, em termos de manutenção das dependências: "os banheiros das crianças são horrorosos”. Há depredação e ausência de condições de uso (sem portas, água, sabonete ou papel higiênico), o que leva a continuarem depredando. Nestas condições extremas, é compreensível que um integrante da diretoria da Redes afirme que, após uma década de atuação, o programa Criança passou a ser demandado, "a maioria delas quer que a gente faça alguma ação dentro das escolas". No entanto, ele também declarou que, somente há cerca de dois anos, haviam percebido que era preciso trabalhar mais com docentes, com as direções escolares e os órgãos superiores da Secretaria da Educação.

\section{Diferença de recursos e de orientação}

Em uma escola, a agente da Redes procurou fazer com que tornasse a haver horário de recreio, porque o período iniciava às 7h30min com aulas até 11h30min, servia-se o almoço e as crianças iam embora. Alegava-se que não havia funcionários(as) disponíveis para "ficar olhando" as crianças durante o recreio. A educadora da Redes pensa que esta é uma concepção de educação na qual as pessoas precisam ser vigiadas, não se procura "estabelecer uma relação de confiança com os alunos" porque isso exigiria um processo educativo e o pessoal da escola não quer ter este trabalho. A mesma educadora foi falar sobre esse assunto na única escola que mantinha o horário de recreio, mas durante o qual aconteciam brigas entre estudantes. A coordenadora pedagógica da escola propôs acabar com o recreio. A contraproposta foi montar tendas no pátio, com livros e jogos disponíveis. Havia jogos na sala de leitura, mas as crianças não podiam usá-la porque se alegava que os jogos atrapalhavam a leitura. A ideia foi aceita em meados de 2009, mas só começou a ser implantada em abril de 2010 devido à opção da Redes em não fazer as coisas no lugar das escolas, tendo o objetivo de dialogar para que se vislumbrem outras soluções e que as escolas as realizem.

Uma coordenadora do programa Criança disse que este tem uma preocupação constante em deixar uma contribuição efetiva para a melhoria da educação, 
considerando a eventualidade de o programa acabar. Esta contribuição seria uma abertura maior para o diálogo e para a participação efetiva das famílias na escola, que não sejam chamadas só "para punir o aluno quando ele fizer bagunça ou tirar nota baixa", que sejam envolvidas no cotidiano, mas não como mão de obra barata em pequenos serviços, tais como os de portaria. A contribuição pretendida também é que docentes tenham atitude reflexiva diante de seu trabalho, um respeito maior pelas crianças que atendem e mais compromisso com a realidade social em que estão inseridos(as): tornar os(as) alunos(as) "mais instrumentalizados para ter um olhar sobre essa realidade e poder transformar", deixando de ser "sempre submissos e passivos tanto na aprendizagem, quanto na vida, quanto na política".

Para a mesma coordenadora, aquele tipo de participação das famílias, de conduta docente e de atividade de estudantes não ocorre devido à desvalorização do magistério, ou seja, docentes lecionando em duas ou três escolas para obterem sua renda, o que toma o seu tempo, cansa muito e impede que planejem e estudem. Ela compara com a situação extraordinária do Colégio Pedro II, em que docentes trabalham com dedicação integral e com horários além das aulas para atender estudantes, pesquisar e desenvolver projetos: "quando ele tem que vir dar aula na favela onde tem tiroteio e ele trabalha em mais dois, três lugares... é quase desumano exigir que essa pessoa estude, planeje, seja supercriativa".

Uma das arte-educadoras da Redes da Maré começou a trabalhar com educação aos 13 anos, colaborando em um projeto chamado Viver com Arte, lecionando no prédio de uma igreja da Maré. Também ministrava aulas de arte em um instituto do Rio de Janeiro, em que eram internados adolescentes infratores. Ela lida com crianças que procuram as aulas de desenho e se inscrevem por sua própria vontade, não por determinação dos pais. Há crianças com 10 anos de idade que começaram aos 7 anos. Há uma turma do período matutino e outra do vespertino, cada uma com cerca de 25 crianças. As aulas são de 90 minutos, duas vezes por semana. Muitas estão inscritas, mas aguardando para iniciar. São alunas de várias escolas de educação básica da Maré e de bairros de fora.

O mesmo trabalho é feito nas escolas locais, onde são seus docentes que montam as turmas. Segundo a arte-educadora, há regularmente atividades ligadas à arte nas escolas comuns, mas são muito presas à história da arte ou às festividades anuais. A sede da Redes conta com uma sala adaptada para as oficinas de arte, que procuram focalizar variações por épocas e artistas. Também são apresentados livros com fotos de obras de arte e esculturas de artistas profissionais para serem vistas e tocadas, com o objetivo de relativizar a noção que as crianças têm de imagem bela. O enfoque procura considerar os desenhos animados e o universo imaginário das crianças, assim como o distanciamento dos padrões de beleza. Por exemplo, indica às crianças que, em cada época, estas costumam desenhar casinhas e que, geralmente, obedecem 
a um padrão reconhecível, mas não retratam a casa real, especialmente a de quem mora na Maré.

Em comparação com as práticas escolares correntes, a educadora criticou sua própria experiência como aluna, que ela considera muito padronizada e persistente: "sentar, olhar para o quadro, escrever o que o professor está mandando ou ler aquele livro que foi destinado e pronto e acabou. Poucos professores têm abertura para você fazer pesquisa, ter outras possibilidades de aprender". Fora disso, são práticas extraodinárias, para as quais a escola não tem recursos e os(as) professores(as) não têm tempo devido à sua imensa carga horária de trabalho. Contrastando com a escola comum, ela acredita ter os recursos necessários, com uma sala destinada para artes visuais, com pia, armário, mesa, cavalete, tintas, entre outros objetos. Distingue também o fato de não ter que estar presa à atribuição de notas. Ela quer que as crianças consigam ter uma percepção visual mais ampla e se expressar não só com o desenho, como também verbalmente, e se relacionar com as outras pessoas, sendo muito além do ensino da arte. A educadora acredita que a escola comum tem desejo de fazer o mesmo, mas não dispõe de recursos e as turmas são grandes.

Um dos diretores da Redes da Maré marca a diferença entre o trabalho educacional desta e o das escolas por este foco na arte, "enriquecendo o currículo" com contação de histórias, circo, orquestra de flautas, passeios culturais, maracatu, atividades com as quais a escola tradicionalmente não consegue trabalhar porque não tem as condições materiais e pedagógicas. Ele acredita que sua organização tem maior mobilidade que organismos do Estado para fazer parcerias que trazem recursos materiais e financeiros. Pensa também que as pessoas que constituem a Redes têm objetivos diferentes da escola ou do Estado: "nossa ideia de transformação estrutural, a ideia de estar engajado politicamente no território, a ideia de ir além da educação formal".

Ao mesmo tempo, estas pessoas veem grande importância na escola para "crianças de origem popular" e a necessidade de a escola estar preparada para atender este tipo de público e entender a realidade local. Entretanto, o magistério foi preparado para atender crianças que são de outra realidade, que "têm acesso a cinema, a teatro, a internet, a livros, uma família que tem uma determinada condição social melhor". O diretor da ONG disse que procuram tratar tais aspectos com docentes das escolas locais, por exemplo, nos encontros de início de ano, nos quais abordam "o que é a favela, o que é a violência na favela, o que é estar num território deste e ser professor". Contudo, o material didático é alheio a isto e mostra imagens de famílias compostas por pessoas brancas, com automóvel, casa de dois andares e empregada doméstica. Por sua vez, há docentes que reclamam de as famílias não acompanharem a vida escolar dos filhos, mas não levam em conta as características das famílias, em que consistiria o acompanhamento e as razões de não ser feito. 
Algumas destas características são de vulnerabilidade. O diretor da ONG destacou que o projeto Nenhum a Menos estava voltado para crianças mais vulneráveis, para quem a escola não estava adequada (NENHUM A MENOS, 2008). Algumas não eram matriculadas porque não tinham certidão de nascimento e iriam se manter analfabetas pelo fato de não terem documentos. Eram moradoras de áreas mais pobres da favela, ficavam abandonadas nas ruas em que se despeja esgoto sem canalização. Os pais não tinham recursos para pagar e ignoravam que tinham direito à emissão gratuita de documentos, bem como a obrigação legal de a escola efetuar a matrícula. O projeto enfrentou as dificuldades de inserir aquelas crianças na escola, atuou durante dois anos com sessenta famílias, conseguiu que as matrículas fossem feitas, mas, muitas vezes, elas se evadiam, em alguns casos porque tinham que trabalhar. Segundo ele, muitas famílias consideram a escola importante, porém, não essencial para a sobrevivência imediata, para a qual é preciso que a criança trabalhe. O projeto procurava orientar os pais para priorizarem a escolarização dos filhos e buscar recursos financeiros por meio de Bolsa Família. ${ }^{1}$ Embora o projeto tenha terminado, esta orientação continuou sendo ministrada nos grupos de pais que foram criados nas escolas pelo programa Criança.

\section{Líderes, agentes e equipes}

A Redes da Maré foi constituída por líderes locais que bfazem parte de uma ínfima minoria com escolaridade de nível superior na Maré. Uma destas pessoas é docente de uma importante universidade pública e pelo menos mais uma é docente de escolas de nível médio.

A rotatividade do pessoal do programa Criança, em contraste com os corpos docentes das escolas, não é significativa. A maioria tem seis a oito anos de dedicação ao programa e sua equipe de coordenação é composta de quatro coordenadores(as) por escolas, duas das quais são responsáveis pela formação. Cada um(a) coordena duas equipes de escolas. Há também quatro coordenadores(as) por área (arte-educação, equipe social, complementação escolar e sala de leitura). São 16 arte-educadores(as). Todas as 57 pessoas que atuam no programa têm estudos de nível superior em diferentes áreas e 23 são moradoras da Maré. Sua experiência profissional é grande, assim como a estabilidade da equipe. Dos(as) 17 arte-educadores(as), cinco são novos(as), os(as) demais tinham entre cinco e seis anos de experiência naquele trabalho. Das sete assistentes sociais, quatro têm pelo menos cinco anos de experiência. As professoras de complementação escolar iniciaram no trabalho em 2009 e somente as que trabalham em sala de leitura são ainda estudantes de nível superior.

Uma das coordenadoras do programa Criança entrevistadas substituiu sua carreira inicial como fonoaudióloga pela de especialista em educação e, por vinte 
anos, trabalhou como coordenadora pedagógica em uma escola privada de elite. Havia nove anos que deixara esta escola para coordenar o programa na Maré. Outra coordenadora é diplomada em Filosofia por uma universidade federal. Já havia exercido a função de coordenadora pedagógica por quatro anos em um projeto de dança de jongo na periferia do município do Rio de Janeiro, assim como coordenou uma estação do Projovem ${ }^{2}$ durante um ano e meio. Segundo ela, os(as) agentes que compõem o pessoal da Redes têm referenciais teóricos e visão de educação muito semelhantes aos do magistério público, mas têm características diferentes porque são pessoas "comprometidas com a transformação social", passam por uma seleção que enfoca o envolvimento com "a realidade social" com a qual lidam e a experiência em trabalhos "com comunidades".

\section{Conclusão}

O caso do programa Criança da Redes da Maré foi descrito em termos de práticas de inovação educacional no sentido de se diferenciarem das práticas educacionais costumeiras, em escolas públicas de educação básica de modo geral, mas, particularmente, em áreas urbanas de grande pobreza. Para examinar a hipótese colocada quanto aos fatores que estariam presentes na gênese da inovação, procurei apurar informação relativa a: tempo de experiência profisisonal dos(as) agentes educadores(as), estabilidade da equipe, qualificação e atuação mobilizadora de líderes.

A extensão da experiência profissional pode ser um fator importante para a iniciativa em inovação educacional, seja porque educadores(as) iniciantes podem ser pessoas empolgadas com a profissão e se empenham em ampliar os efeitos de seu trabalho, seja porque as mais experientes podem ser mais autoconfiantes e perseguir seus propósitos com atitude mais segura. A estabilidade das equipes será relevante para a inovação se estas dispuserem de mais consensos acumulados sobre o ambiente das suas práticas educacionais, assim como é possível que uma rotatividade maior reduza compromissos entre integrantes, encorajando algumas destas pessoas a seguir caminhos próprios e à experimentação.

A atuação mobilizadora de líderes, por sua vez, tanto pode incentivar iniciativas inovadoras entre educadores(as) quanto pode constituir-se em iniciativa própria e alheia ao engajamento deste(as). No que diz respeito à qualificação profissional de líderes locais, pode determinar um posicionamento crítico em relação à educação exercida regularmente e um empenho em práticas diferenciadas.

Nitidamente, tais fatores estão presentes no caso Redes da Maré. Os(as) agentes contam com significativa experiência profissional e a rotatividade é baixa, assim como os(as) líderes da ONG se definem por sua atuação mobilizadora, sendo 
também experientes e tendo um nível extraordinariamente alto de escolaridade. Tudo isso se conjuga para a ocorrência de práticas muito diferentes das que costumeiramente ocorrem nas escolas, ainda que não assegure que os melhores caminhos tenham sido escolhidos.

\section{Notas}

1. Programa do governo federal (Ministério do Desenvolvimento Social e Combate à Fome), de transferência direta de renda, atende mais de 12 milhões de famílias em todo o território nacional. Disponível em: <http://www.mds.gov.br/bolsafamilia>. Acesso em: 27 dez. 2010.

2. Programa do governo federal, cujo objetivo é preparar o jovem para o mercado de trabalho e para ocupações alternativas geradoras de renda. Podem participar do programa os jovens desempregados com idades entre 18 e 29 anos, membros de famílias com renda per capita de até meio salário mínimo. Disponível em: <http://www.mte.gov.br/projovem/default.asp>. Acesso em: 27 dez. 2010.

\section{Referências}

CRAFT, A. The limits to creativity in education: dilemmas for the educator. British Journal of Educational Studies, Oxford, v. 51, n. 2, p. 113-127, jun. 2003.

CRAIG, C.J. No satisfaction: a case of "the monkey's paw", top-down school reform, and the conduit. Curriculum Inquiry, Toronto, v. 31, n. 3, p. 341-350, 2001a.

CRAIG, C.J. The relationship between and among teacher's narrative knowledge, communities of knowing, and school reform: a case of "the monkey's paw". Curriculum Inquiry, Toronto, v. 31, n. 3, p. 303-331, 2001 b.

DIDASKALOU, E.S. Current obstacles to change in Greek primary schools: implications for managing behaviour problems. European Journal of Education, Oxford, v. 37, n. 4, p. 473-482, 2002.

DRAKE, C.; SHERIN, M. Practicing change: curriculum adaptation and teacher narrative in the context of mathematics education reform. Curriculum Inquiry, Toronto, v. 36, n. 2, p. 153-187, 2006.

FARRELL, J.P. Why is educational reform so difficult? Curriculum Inquiry, Toronto, v. 30, n. 1, p. 83-103, 2000.

FARRELL, J.P. Can we really change the forms of formal schooling?: and would it make a difference if we could? Curriculum Inquiry, Toronto, v. 31, n. 4, p. 389-398, 2001.

GLÓRIA, D.M.A.; MAFRA, L.A. A prática da não retenção escolar na narrativa de professores do ensino fundamental: dificuldades e avanços na busca do sucesso escolar. Educação \& Pesquisa, São Paulo, v. 30, n. 2, p. 231-250, ago. 2004. 
$\mathrm{HATCH}, \mathrm{T}$. The usual monkey business: a case of repetition and reform; a response to Cheryl Craig's 'The relationships between and among teachers' narrative knowledge, communities of knowing, and school reform: a case of 'the monkey's paw". Curriculum Inquiry, Toronto, v. 31, n. 3, p. 333-340, 2001.

HUBERMAN, A.M. Como se realizam as mudanças em educação: subsídios para o estudo do problema da inovação. Trad. de Jamir Martins. São Paulo: Cultrix, 1976.

LAWTON, D. Book review “Images of educational Change"[ ed. by H. Altrichter; J. Elliott. Buckingham: Open University Press, 2000]. British Journal of Educational Studies, Oxford, v. 49, n. 4, p. 446-472, 2001.

LEVIN, B. How to change 5000 schools: a practical and positive approach for leading change at every level. Cambridge, Mass.: Harvard Educational, 2008.

NENHUM A MENOS ... e muitos esforços a mais!: a experiência de inclusão escolar de crianças e jovens do Bairro Maré, no Rio de Janeiro. Rio de Janeiro: Redes de Desenvolviemnto da Maré, 2008.

PARSONS, C.; FIDLER, B. A new theory of educational change - punctuated equilibrium: the case of the internationalization of higer education institutions. British Journal of Educational Studies, Oxford, v. 53, n. 4, p. 447-465, 2005.

REDES. Quem somos. 2011. Disponível em: <http://www.redesdamare.org.br/quemsomos/apresentacao >. Acesso em: 2 dez. 2011.

REDES. Programa Criança Petrobras. 2011a. Disponível em: <http://www.redesdamare. org.br/quem-somos/apresentacao>. Acesso em: 2 dez. 2011.

TORRES, R.M. Reformadores y docentes: el cambio educativo atrapado entre dos logicas. In: CÁRDENAS, L.; RODRIGUEZ CÉSPEDES, A.; TORRES, R.M. El maestro, protagonista del cambio educativo. Bogotá: Convenio Andrés Bello; Magisterio Nacional, 2000. p. 161-312.

TURA, M.L.R.; MARCONDES, M.I. Heterogeneidade, ciclos e a prática pedagógica. Revista Brasileira de Estudos Pedagógicos, Brasília, DF, v. 89, n. 222, p. 242-258, 2008.

TYACK, D.; CUBAN, L. Tinkering toward utopia: a century of public school reform. Cambridge, Mass.: Harvard University, 1995.

Recebido em 13 de fevereiro de 2012.

Aprovado em 26 de abril de 2013. 